\title{
3. Mechanisms, conditions and outcomes: theories of policy change
}

This chapter does not focus on multilevel governance. It widens the perspective on mechanisms of policy change, that is, political processes leading to decisions of executives, parliaments and civil servants which alter the status quo in a policy field. For a long time, political scientists have been interested in these kinds of decisions because elected representatives regularly promise to improve policies but struggle to really change existing ones, not least under conditions of institutional and societal complexity. Certainly, whenever responsible actors holding political office make a decision, they normally act, and actions cause change. We cannot rule out that politics results in non-decisions or inaction (Howlett and Cashore 2014: 17), but if a matter is on the agenda of a government or another political organization, this is not an attractive alternative for responsible executives, who are accountable to parliaments or citizens and supervised by the media. However, even if these actors are willing to decide on issues, they do not always change the status quo as intended. ${ }^{1}$ In democracies, they have to take into account a plurality of competing interests, and many organized interest groups have capacities and means at their disposal to influence the decision of a government. In addition, institutional and partisan veto players can thwart or slow down policy change.

Whenever political scientists have studied or theorized policy change, they have in mind decisions which redirect the course of a policy and significantly modify the status quo. ${ }^{2}$ This is an issue which particularly deserves attention in democracies. On the one hand, meaningful free elections always can lead to a change in government, and this implies that voters expect a corresponding change of policies. On the other hand, changing a policy to a significant extent is difficult in democratic systems where power is divided and governments are subject to the rule of law and face pressure from organized interest groups. Accordingly, most theories addressing policy change in complex political systems tell us that gradual change is the rule and significant or radical change is the exception. Path-dependence of institutions, rigidity of power structures and patterns of interactions such as policy networks or public-private policy communities emerging in a stable institutional framework, or powerful veto players have been identified as the main causes. As Charles Lindblom argued, 
incrementalism should be taken as an appropriate strategy of policymaking in the face of complex agendas (Lindblom 1959).

Even if a government is able to change a policy, this does not necessarily lead to a solution of the addressed problems. Deficits of implementation can undermine the effectiveness of a new policy. Lack of administrative capacities, inappropriate procedures or powerful opponents using their influence on the implementation process to obstruct a policy can water down the execution of a new law or programme compared to the original intentions. In addition, a policy may turn out as inappropriate to 'steer' societal actors, groups or subsystems of a society as envisaged. Sociological theories mainly consider social, technical or environmental conditions as relevant factors enabling or inhibiting problem solving by public policies, although they also might reflect that these conditions affect conflicts, power relations or interactions in the political process of governance (Mayntz 2016). As we are interested in multilevel governance, we can leave aside the discussion on whether, how or to what extent these societal conditions impact on policy change or policy innovation. We will touch upon these questions in the context of theories explaining change as a sequence of stability and critical events and when discussing conditions. However, the focus of this chapter will be on the process of policymaking and on mechanisms driving and shaping this process.

Over the last few decades, theories explaining policy change became more differentiated and more precise in their description of mechanisms and conditions (Capano et al. 2019). On the one hand, scholars have taken into account different aspects of policymaking and have analysed the interplay of institutions, interactions and ideas. On the other hand, studies on institutions and politics have increasingly addressed or emphasized dynamics rather than stability or rigidity. Research has revealed that political decisions may initiate self-reinforcing processes in policy fields leading to sequences of change. Moreover, it has drawn attention to the fact that policymakers can shape the conditions constraining their power to make policies and can create new options for significant change, which may also result from 'policy dynamics'. Furthermore, the 'ideational turn' in policy science has drawn attention to the relevance of knowledge, to communicative processes and policy learning (Dunlop and Radaelli 2020). All these processes might even amount to a transformative development, which is triggered by significant change of a policy regime, affects values, institutions, power relations and interrelated substantial aspects of a policy, and over time advances towards a new path of evolution or a transition towards a new regime (Meadowcroft 2009). The following sections draw on these different theories, outline mechanisms of policy change and discuss selected conditions affecting the operation of these mechanisms. 


\section{MECHANISMS OF POLICY CHANGE}

In social science, mechanisms explain the causal relationship between an initial condition and an effect or outcome. Without going into the details of the debate on mechanisms, whether they are real or just theoretical constructs and whether we can observe them or not (for a summary, see: Broschek and Paquet 2018), I use the 'core meaning' that John Gerring has identified in a review of the literature. Accordingly, a mechanism is 'the pathway or process by which an effect is produced' (Gerring 2008: 178). As social processes, mechanisms are activated by individual or collective actors and evolve according to a particular 'logic' of interaction. Effects can be observed in the behaviour of individuals, in the activities of collective actors (organizations, associations), in changes of structures (power relations, allocation of resources) or in the operation of systems (institutions, regimes, social systems). Interested in policy change and innovation, we can qualify effects as outcomes in relation to the status quo, as intended or not intended, as effective or failed regarding the task to be fulfilled, and as lasting or short-lived (see Chapter 1). Policies can evolve in linear processes but can also reveal inherent dynamics through feedback effects. For this reason, an outcome is not determined by a single cause. It is causal processes which matter. Moreover, the effects of a mechanism vary depending on the conditions. They will be considered in the next section.

Theories of policymaking and institutional change delineate different mechanisms, although they are not always spelled out as such. Moreover, mechanisms and conditions are often not clearly distinguished. The critical review of the literature demonstrates that this confusion can lead to unfounded conclusions. In order to understand the dynamics of policymaking and the impact of different conditions, it seems to be suitable to differentiate between mechanisms maintaining continuity, which implies incremental or gradual change, and mechanisms resulting in substantial change. Mechanisms are set in motion by actors and the interactions of actors, which are subject to particular constraints, pursue strategies and communicate with others. These three categories of interaction can be used to map mechanisms. Rather than using them as an alternative explanation, we should consider them as causal processes which usually co-evolve and mutually reinforce their particular effects.

\section{Policymaking as Constrained Interaction}

The first set of mechanisms implies that actors are subject to institutions or rules, pressure from organized interests and power structures inherent in policy regimes. In general, these constraints prevent actors from significantly changing a policy. From a normative point of view, constraining the power 
of policymakers responsible for providing public goods or solving collective action problems is ambivalent. On the one hand, there are good reasons why policymaking is guided by rules and why institutions divide and balance power to make and implement decisions. There are also good reasons which speak for the participation of private actors having a stake in a policy and providing expertise. On the other hand, constraining action by rules or stakeholder participation can prevent policymakers from effectively fulfilling their tasks or mandates and from solving problems, not least if rising conflicts or public debates call for significant revision of an existing policy. By establishing rules and norms, institutions enable coordinated actions of policymakers, but an increasing discrepancy between constraints and the need for change can create a critical situation, which facilitates or prompts disruptive developments.

This ambivalence of constraints is reflected in the widely discussed dilemma between effectiveness and legitimacy in multilevel governance (Scharpf 2000) or between differentiation and interdependence in complex organizations (Lawrence und Lorsch 1967). It finds expression in processes oscillating between periods of continuity or incremental change and periods of radical change. This sequential evolution has surfaced as an influential concept in theories on institutional change and policy change. Accordingly, constrained action maintains continuity, that is, it safeguards stability or adjustment through gradual evolution, as long as all actors representing crucial interests profit from compliance with rules or as long as balanced power structures prevent change. If this is no longer the case, disruptive change can occur.

Historical approaches in particular draw attention to the fact that political decisions materialize in the creation of institutions, and institutions shape the further evolution of politics according to their own logics. By solving collective action dilemmas, they provide essential functions for policymaking. In sociological terms, they constitute a framework of recognized principles and norms guiding actors towards common goals, reducing uncertainty and restraining conflicts. In economic terms, they constitute investments which generate increasing returns and reduce transaction costs, whereas changes cause uncertainties and high costs of transformation (Pierson 2004; Thelen 1999). In policy science, scholars use the concept of 'regime' to indicate that over time policies condense in a configuration of programmes, budgets, interest constellations, patterns of interactions and power structures (May and Jochim 2013). Such arrangements have been identified in economic policy (Hall and Soskice 2001), environmental policy (Jahn 1998) and, not least, in social policy. In his seminal book on worlds of welfare capitalism, Gøsta Esping-Andersen argued that policies coping with the social conflicts of industrialized societies and capitalist market economies not only materialized in rights and benefits for people in need, but also in institutions and power structures among collective actors. Thus they became 'powerful societal mecha- 
nisms which decisively shape the future' (Esping-Andersen 1990: 221). The 'trajectory' of social policy is defined by the particular welfare-state regimes, 'each organized around its own discrete logic of organization, stratification, and social integration' (ibid.: 3). Peter J. May and Ashley E. Jochim pointed out that 'key components of durability are the path-dependence of institutional structures and funding that are put in place, and the interest support that works to hold overseers accountable and resist efforts to weaken policy implementation' (May and Jochim 2013: 433). In research on agenda setting, the balance of power, emergent policy communities and a predominating 'policy image' - that is the way in which participants in a policy process perceive problems - have been highlighted as modules of social mechanisms preventing change (Baumgartner and Jones 1993).

Neither institutions nor policy regimes are durable per se, but they establish mechanisms fostering stability which are summarized as path-dependent evolution or positive (self-reinforcing) feedback processes maintaining an equilibrium of power relations. Consequently, significant change is explained as the interruption of these continuities. Scholars interested in historical political development or historical institutionalism introduced the concept of a 'critical juncture'. In policy science, a similar concept was characterized as a 'punctuated equilibrium', which implies that change results from an intermittent dissolution of an existing balance of power stabilizing the agenda of a government and the policies ensuing from this agenda (Baumgartner and Jones 1993). The punctuation of stability occurs under particular circumstances, when a 'window of opportunity' to deviate from an established policy opens (Kingdon 2003), or when a sudden, rare and potentially harmful 'focusing event' calls for revising or expanding the political agenda and mobilizes interest groups against existing policy communities (Birkland 1998). Therefore, time and sequences constitute fundamental dimensions to be considered in studies on institutional and policy change. Yet, in order to go beyond a pure analytical description of change, theories have to uncover different mechanisms of policymaking in order to understand the processes leading to these crucial situations and to explain their consequences.

Obviously, changing institutions or the constitution of a political system is more difficult than changing the substance of a policy. This finds expression in the popularity of the concept of path-dependence in historical institutionalism. It comprises stabilizing mechanisms like norm-oriented interaction, socialization and routinization, or increasing returns of collective actions guided by rules. The notion of a critical juncture refers to an exceptional situation, an opportunity to deviate from an existing path of development and to significantly change institutions. Yet like a juncture of a rail track, this situation does not determine the future development. Apart from different options to proceed, 
it offers a choice between deviating from the old path or keeping the direction, between changing institutions and sustaining them. Accordingly,

critical junctures are characterized by a situation in which the structural (that is, economic, cultural, ideological, organizational) influences on political action are significantly relaxed for a relatively short period, with two main consequences: the range of plausible choices open to powerful political actors expands substantially and the consequences of their decisions for the outcome of interest are potentially much more momentous. (Capoccia and Kelemen 2007: 343)

Although scholars have tried to understand what happens in these crucial situations, most of them highlight the 'contingency' with the consequence that neither the choice of actors nor the future development can be predicted or explained (Mahoney 2000: 513). In contrast to 'path-dependence', the concept of critical junctures does not point out particular social mechanisms.

Theories of policy change presuming a sequence between continuity and change are confronted with the same problem. When Frank Baumgartner and Brian Jones, for instance, characterized dynamics of agenda setting in a policy process as a punctuated equilibrium (Baumgartner et al. 2017; Baumgartner et al. 2009), they explained longer periods of stability by the complexity of issues and the bounded rationality of policymakers. Complexity is reduced by institutions and framing of issues. Moreover, governments assign special policies to different departments, which cope with interdependence among the divided policies by incremental adjustments of their decisions. These adjustments between specialized policy communities reveal bounded rationality. They allow the maintenance of patterns of interactions and cognitive-normative frames of policymakers, both of which emerge in normal interactions of actors belonging to a particular community. From time to time, however, this gradual development within a stable microstructure of interaction and power does not suffice to meet the demands for change, provoked by 'social processes' and expressed in politics by parliaments, cabinets or presidents which are responsible for the overarching goals of public policy. While continuous adjustments between policy sectors and policy communities can maintain an equilibrium of power, tensions with high politics and the institutions of government lead to short periods of disruptive change. When it comes to explicating the mechanism linking tensions and significant policy change, Baumgartner and Jones, like proponents of historical institutionalism, introduce actors without explaining how they initiate, control or accomplish significant policy change.

A similar temporal pattern of the policy process has been conceptualized with the 'multiple streams' approach. It can be traced back to concepts which John Kingdon formulated in his policy studies (Kingdon 2003) and which have been further elaborated and developed into a theory explaining far-reaching or rapid policy change (Zohlnhöfer and Rüb 2016). According to this theory, the 
situation triggering significant change does not result from tensions between the incrementalism of constrained policymaking and pressure from social processes, but from the conjunction of three processes: first, the rise of a problem; second, the dynamics of politics driven by election campaigns, pressure from interest groups or party competition; and third, the evolution of policy ideas and policy alternatives. The opportunity for change arises from the linkage of these 'streams', when the focus of attention is directed to particular problems, when powerful political actors support a solution of the problem, and when policies are at hand that are technically feasible, financially viable and acceptable for those affected. The coupling of these processes should open a 'window of opportunity' which can be used by 'policy entrepreneurs' in order to advance a new policy. These actors not only advocate a new policy but also serve as 'power brokers and manipulators of problematic preferences and unclear technologies' (Zahariadis 2007: 71). Thus, agency matters, because individual or collective actors have to respond to the coincident concurrence of the streams. When the policy window opens, political actors have to shape the agenda of politics and select decisions from the set of alternatives. If they miss the opportunity, the status quo remains in place or incremental policymaking continues. Acting under time constraints, guided by an institutional context and involved in policy networks, policymakers have to rely on policy entrepreneurs who should mobilize coalitions supporting change.

'Path-dependence', 'punctuated equilibrium' and the 'multiple streams' are instructive models to comprehend processes of institutional and policy change, processes which usually are closely linked. Scholars have extensively discussed what these approaches can explain if they are meant and applied as theories. On a closer look, they provide frameworks which include different theoretical concepts and assumptions on causes and effects. They take into account structures, processes and actors, consider micro- and macro-phenomena, and identify conditions and social mechanisms. On the one hand, they provide a menu of arguments to explain change; on the other hand, they plausibly describe the interplay of continuity and change over time. This is the reason why these approaches became popular. When scholars apply them to particular cases, they regularly emphasize specific mechanisms and conditions (Herweg 2013). However, they rarely distinguish clearly causal mechanisms, conditions or endogenous or exogenous factors driving the change of even independent and dependent variables. As Giliberto Capano rightly concludes: 'The most sophisticated models of policy change and development, due to their underlying combinative causal logic, tend to design causal mechanisms which mix (but too often simply sum up) both types of explanatory variable' (Capano 2009: 17).

If we take these 'theories' as 'mechanismic' approaches to explain change, they first and foremost refer to the sequential nature of the process which 
matters, a sequence which is created by tensions between the stabilizing effects of an institutional configuration or policy regime and events triggering change (see Benz and Sonnicksen 2018). In general, these approaches confirm that significant change is the exception rather than the rule, at least under the condition of complex institutions, interdependent issues and the number of veto players and stakeholders involved in policy processes. Yet the coincidence of critical junctures, streams falling together or tensions arising from political pressure to deviate from incremental policy adjustments alone cannot sufficiently explain why and how significant change occurs. The focus on actors and choice underestimates power structures established in formal institutions and implementation processes. If we are interested in policy innovation, crucial situations can only be taken as the context of favourable or unfavourable developments.

To explain policy change, we need to know what happens after institutional constraints had relaxed, after an agenda of a government had changed and after responsible actors had decided to revise policy. For a long time, this aspect was addressed in implementation research, in studies determined to investigate why ambitious programmes often lead to limited effects. Yet while implementation deficits mostly confirm the incremental evolution of policies by pointing to adjustments of policies to local contexts, another theory has drawn attention to a particular source of dynamics. It emphasizes feedback mechanisms between output and input in sequences of policymaking, or - to put it in another way - it takes effects of a previous policy regimes as a cause of ensuing policymaking.

The notion of 'policy feedback' surfaced in studies on policymaking in the US federal system, when Paul Pierson introduced and defined the concept (Pierson 1993). Starting from the theoretical claim that 'policies produce politics' (ibid.: 597) - a remarkable modification of Theodore Lowi's statement that 'policy determines politics' (Lowi 1972: 299) - Pierson discerned various mechanisms implied in this claim, such as incentives resulting from previous policies, the mobilization of interest groups that are attracted by public benefits and services, increased governance capacities allowing office holders to expand their activities, extended power for executives to initiate or implement additional programmes, and changed perceptions and expectations of mass publics in response to economic or welfare policies. Accordingly, existing policies induce governments, interest groups and citizens to learn, and to revise their preferences, perceptions and ideas. In the course of time, these mechanisms modifying politics influence future policymaking. Scholars who have advanced this theory differentiate between positive and negative feedback, with the former stabilizing a policy and the latter causing self-reinforcing dynamics (Béland and Schlager 2019; Daugbjerg and Kay 2020; Jacobs and Weaver 2015; Jordan and Matt 2015). 
Understanding feedback effects has turned out as particularly relevant to explain reform policies. They evolve in a 'dynamic process in which forces seeking to protect a reform may be opposed by forces seeking to undo it' (Patashnik 2008: 25). By considering these processes, researchers shed new light on the character of policy change. Reforms of existing institutions and regulations, a reallocation of funds or modification of tax laws or service delivery 'reconfigure the political dynamic' (ibid.: 155). Regardless of whether they are successful or they fail, reforms produce change on their own. New institutional settings, redistributive effects, revised power constellations among interest groups or social learning of actors affected by a changed policy can contribute to a post-reform development. As Andrew Karch and Shanna Rose showed in their study on policy reform in US federalism, the interaction of governments in a multilevel constellation constitutes a particular source of policy feedback, both positive and negative (Karch and Rose 2019). Studies on constitutional change have revealed that processes aiming at amendments of the law have effect on the real constitution regardless of whether amendment laws have been passed or not (Benz 2016a: 177-98). The concept of the 'Europeanization' of policies in EU member states (Radaelli 2003) highlights a similar dynamic effect of reform, since the adaptation of national governments, administrations, parties or interest groups to the rising authority of European institutions changes the conditions for multilevel policymaking.

These feedback mechanisms result from the interplay of continuity and change and the sequential or recursive development of policymaking. They emerge because actors face multiple constraints such as norms and rules, power structures or pressure arising from contingent situations. However, policymaking is also constrained, because actors are mutually dependent on each other and therefore compelled to react to others' decisions or actions. In contrast to institutions or policy regimes which support continuity as long as their self-reinforcing dynamics is not interrupted, mechanisms inherent in patterns of interactions can be conducive to either continuity or change. Other things being equal, cooperation leads participants to stick to the status quo but encourages permanent adjustment, unlike competition which drives actors to change and stimulates innovation.

Certainly, governments, administrations and private actors can cooperate to implement a new policy. Executives from different departments can form a coalition to build pressure for policy change against those who defend an existing policy or policy regime. However, in order to change the status quo, these actors have to come to an agreement on a new direction of a policy. In principle, cooperation aims at pooling resources and power in order to better achieve common goals, but more often than not, individual actors have their own preferences on a policy. Hence mixed motives drive their behaviour in negotiations. On the one hand, they prefer an agreement on a policy to uncoor- 
dinated action, on the other hand, they pursue their own interests or the interests of the group, organization or government they represent. Revising an existing agreement either requires that actors change their preferences or settle their disputes in package deals, whereas compromises often end with the lowest common denominator defined by their overlapping preferences (the 'win set', that is 'the set of outcomes that can defeat the status quo' [Tsebelis 2002: 21] if every participant can exercise veto power). In policymaking, actors usually are not free to change their preferences because they are bound to mandates or are committed to a party, government or interest group. Package deals are difficult as they usually require the extension of an agenda and involve increased transaction costs. Hence compromises on gradual change seem to be the most likely outcome. Actors can avoid this tendency to incrementalist policymaking by threatening to exit or by really ending their cooperation. However, institutional rules requiring cooperation or effective mutual dependence may rule out this option. The Joint-Decision Trap outlined in the previous chapter occurs under these particular conditions (Scharpf 1988).

In economics, competition appears as a mode of coordination which promotes innovation. Joseph A. Schumpeter once characterized the capitalist market economy as a process of 'creative destruction' through competition, a process, 'which commands a decisive cost or quality advantage and which strikes not at the margins of the profits and the outputs of existing firms but at their foundations and their very lives' (Schumpeter 1943 [2010]: 74). Thus, he emphasized the pressure for innovation inherent in the market mechanism, and he observed the same mechanisms in party politics which had evolved in liberal democracies. Contemporary proponents of institutional economics would argue in a more differentiated way and point out the persistence of firms as organizations and the rigidities caused by routines and rules. Nevertheless, they would agree that actors or organizations facing competition are compelled to adjust their behaviour and revise their activities to improve their position in relation to others.

In policymaking, governments compete, such as, for instance, regional governments in a decentralized federal state or national governments in international relations. Within governments, party competition affects decisions of parliaments and of the executive, even if it does not, as Schumpeter suggested, determine politics. In general, these mechanisms of politics generate their own dynamics. They encourage change and punish those who stick to the status quo. However, policy change does not occur under all conditions in a process of competition. Competing actors interact in a 'non-cooperative game'. Without having the opportunity to exchange information in negotiations and with limited knowledge about the consequences of their decisions or actions, governments or parties coordinate their policies via mutual adjustment, because they are motivated or compelled to react to the policies of rivals, 
with whom they compete for limited resources or for benefits such as mobile taxpayers, recognition in public or votes in elections. The direction of change can be influenced by actors who take the first step of altering a policy in the iterative game of action and reaction. Yet those who take the lead do not always profit from the first-mover advantage. When governments of states or local governments try to attract firms by lowering taxes, investing in utilities, extending public services or promising subsidies, they might be forced to increase public debts and lose elections when citizens doubt that this policy will pay off.

In democracies, both cooperation and competition are complex processes including multiple actors, patterns of interactions and mechanisms. More often than not, competitors cooperate in alliances or coalitions, although they remain and behave as rivals. This is a typical situation in coalition governments or in a federal system where governments supported by opposing parties have to negotiate agreements. In general, partners in cooperation and rivals in competition are agents and accountable to 'principals'. While they profit from information asymmetry, they nonetheless cannot thoroughly enjoy autonomy as they act for others. Policymakers have to take account of the will of parliaments or majority parties, electorates and organized interest groups. Likewise, public or private organizations are affected by the responses of members, supporters or clients to their decisions or performance. Therefore, additional social mechanisms influence how cooperation and competition shape policymaking and outcomes. In his study on the dysfunctional operation of firms, organizations and states, Albert O. Hirschman discerned 'exit' and 'voice' as typical reactions of customers, party members or citizens to deficient performance or processes of decline (Hirschman 1970). In politics, exit is an option available for individual actors, voice might be raised by individuals (for instance by submitting an objection against an administrative decision, by sending a petition to parliament or by making an argument in negotiations), but in view of public policies, it generally becomes effective as collective action.

In competition, exit, whether it is threatened or carried out, intensifies pressure for change. Private firms often announce they will leave a municipality, city, region or country if the incumbent government refuses to alter a policy running against economic interests. Yet, in general, it is not exit which influences the policies of a government. Rather it is the prospect of attracting investors and taxpayers by providing appropriate goods and services. For a similar reason, governments in well-off countries try to prevent the immigration of peoples from countries where responsible office-holders fail to provide peace and basic public goods or violate the fundamental human rights of citizens, because they expect increasing fiscal burdens. Closing borders is an option for avoiding the pressure of competition, although it has significant negative side effects for a government. Likewise, exit bears high costs for citizens and firms. 
Hence it is more likely that citizens or firms raise their voice and that public opinion or protest motivates a government to change policies when facing competition, while exit remains a last resort.

Cooperation evolves in negotiations and therefore allows participants to articulate their interests. Bargaining and arguing (Elster 2000) constitute the main modes of voice in this context. As a rule, they contribute to achieve modest policy change, with the bargaining behaviour of participants allowing only incremental deviation from the status quo, whereas arguing increases the probability of innovative decisions. Exit is an option in cooperation, which actors can bring into play with different intentions. However, it can lead to unintended consequences. By threatening to leave negotiations or cooperation, actors can improve their bargaining position if this is a credible strategic move. This way, they can advance policy change, if this conforms to their preferences. On the other hand, if the other participants do not respond with sufficient concessions, actors may be forced to actually exit. In any case, exit threats lead to confrontation. In consequence, coordinated action is blocked, and if coordination is essential for making a policy, exit prevents even marginal change. As Hirschman pointed out, the loyalty of members of a group, organization or citizens to a political community (a nation) increases the costs and reduces the probability of exit (Hirschman 1970: 77) and hence the credibility of a threat of this move. Accordingly, it motivates actors to raise their voice. Yet loyalty can also preserve groups or coalitions which support the persistence of policies or policy regimes. In general, it favours continuity.

Most theories of policymaking outlined so far emphasize constrained interaction as a cause of continuity, and they locate these constraints in institutions and interactions. Of course, other factors constraining action can prevent policy change, such as a lack of resources, limited powers or rules entrenched in constitutional law. In contrast to these given conditions, institutions and interactions do not determine policymaking but establish mechanisms that prevent actors from uncoordinated and arbitrary behaviour and that actors can influence to a certain extent. While continuity prevails under usual conditions, change is possible over time, when specific circumstances allow actors to initiate change and when they exploit critical events to change routinized processes of interaction. Like sequences of institutional development and recursive processes in complex policy regimes, the effects of loyalty, exit and voice vary over time. When loyalty weakens, actors opt for voice and exit in a sequence of reactions (Dowding et al. 2000: 473-5). Therefore, actors can find ways to surmount or circumvent different constraints inherent in institutions and interactions. They do this by strategic action and this changes interaction in policymaking. 


\section{Policymaking as Strategic Interaction}

Strategic action is targeted at specific objectives, which are approached in a series of planned steps, often in an indirect way, by adjusting to constraints or circumventing them, and by seizing favourable occasions. Its relevance in theories of policymaking can be explicated by briefly discussing veto players and the theory based on this concept. George Tsebelis elaborated this theory in order to compare how different systems of governments work, or, more precisely, how the various institutional configurations enable or constrain policy change (Tsebelis 2002). Unsatisfied with the usual typologies of comparative governments, he reduced institutional variation to the quantity and types of corporate actors whose assent is necessary to make decisions on policies. Chambers in bicameral legislatures, majority parties or parties cooperating in a coalition, and executives in joint-decision making are cases in point. Although Tsebelis does not spell out this aspect, his institutionalist explanation implies a mechanism of interaction, a process in which veto players express their preferences, search for issues they can agree upon, and finally come to their vote.

Veto player theory states that the more actors with veto power are involved in policymaking and the more these actors' preferences diverge, the lower the probability of a policy change or the narrower the scope of change (Tsebelis 2002: 136-60). Considering a large number of policies, this claim may be true, as Tsebelis and others have confirmed in comparative research, usually by operationalizing change with the number of significant laws passed in a certain period of time. However, political actors responsible for a policy and accountable to citizens or affected groups have an interest in avoiding deadlock and therefore tend to refrain from using their veto power. More often than not, they search for compromises in negotiations, and, in consequence, veto power turns into bargaining power. Whenever a policy is on the agenda of governments, incremental change is more likely than no decision. For this reason, the number of laws passed in a certain time span is not a good indicator for measuring the policy effects of veto players. Rather it is the quality and the deviation of a policy from the status quo which can be explained by this theory. Beyond institutions, strategic interactions have to be taken into account in an explanation of change.

It should not be denied that the strategic interaction of veto players rarely brings about significant policy change. In fact, it makes incremental adjustment possible in an institutional setting which is prone to cause deadlocks. Theories of historical institutionalism and punctuated equilibrium suggest another conclusion. They introduce strategic actors to understand what happens in exceptional situations, which facilitate or enforce significant change but also increase uncertainties and complexity. In these analytical frameworks, 'policy 
entrepreneurs' appear as facilitators and drivers of change. These particular actors actively participate in policymaking and profit from a high degree of autonomy, authority and knowledge, although they cannot necessarily rely on formal power or resources. They should contribute to overcome the constraints of institutions or structures and the lock-in effects of polarized negotiations, find ways to solve collective action dilemmas, and moderate the power of veto players or the effects of self-reinforcing feedback in policy dynamics. With their 'knowledge, power, tenacity and luck', they are 'able to exploit windows of opportunity and heightened levels of attention to policy problems to promote their "pet solutions" to policymakers' (Cairney 2012: 271). Interested in providing a public good (John 2012: 185) rather than pursuing egotist aims, and endowed with strategic skills, they are expected to prevent policymakers from ending in decision traps. In addition, they should help to avoid frictions, turn tensions into productive energies and find innovative solutions. In literature influenced by management studies, policy entrepreneurs are defined as 'energetic actors who work with others in and around policymaking venues to promote policy innovations' (Mintrom 2019: 1) or actors who 'catalyse dynamic change' (ibid.: 11).

Besides defining the functions of policy entrepreneurs and indicating their different roles in policymaking or their relevance in different stages of policy processes, scholars have also tried to categorize characteristic abilities and activities (Mintrom 2019: 8-20). The concept has found particular attention in literature on transition management (Loorbach 2007). There is no need to go into the details of this literature. It will suffice to note that theories explaining significant policy change apparently need to include actors and strategic interaction. Entrepreneurial actors drive change, irrespective of their formal position, by adopting leadership, either due to their power or as independent experts. They invent solutions for problems or conflicts, find ways to circumvent constraints and encourage other actors to take the risk of innovative decisions.

The strategies of veto players and policy entrepreneurs differ as the latter focus on outcomes and the former on decision making. Entrepreneurial behaviour is particularly important to prevent policymakers from falling into the traps of social dilemmas, like, for instance, the Joint-Decision Trap (Scharpf 1988) or the 'negotiator's dilemma' (Lax and Sebenius 1986). In this case, it is not expertise which is relevant but the preparedness to take the risk. Political leaders who express that they are willing to negotiate or who make concessions in negotiations risk failing with this strategy or losing in the bargaining process. Party leaders advocating policies promising future benefits at significant short-term costs risk losing elections. Heads of private organizations or speakers of civil society associations risk being forced out of their position when they conclude agreements with a government or an administration and 
accept compromises. However, exactly these strategies can work to overcome a looming gridlock in policymaking and to achieve significant changes to the benefit of those affected by policies. If these strategies prove successful, the outcome can be ascribed to the merit of a policy entrepreneur.

In management literature, strategic actors pushing for institutional change are called 'change agents'. James Mahoney and Kathleen Thelen used this term in their actor-centred version of institutionalism to categorize different types of actors and to explain different processes and outcomes of institutional change. Some of these agents seek to preserve institutions, but unintentionally contribute to change because they undermine rules, either by using them in an opportunistic way or by acting contrary to the spirit or purpose of institutions. Others intentionally infringe rules or mobilize for reform (Mahoney and Thelen 2010: 22-31). Obviously, most of these strategies are linked to particular policies, which demonstrates that policy change cannot be separated from institutional change and institutions often change in the course of policymaking. They can constitute a particular strategy to renovate an established policy regime.

In contrast to strategic use of veto power and strategies provoking endogenous and gradual change, entrepreneurial strategies are rare in policymaking. More often we find coordinated actions to defend an existing policy or to initiate change. Networking appears as a typical defensive strategy supporting continuity. Often considered as a way to increase individual profit in private business, it mainly serves to form advocacy coalitions for particular policies in government and public administration. Networks link actors by relations of trust and exchange of information, and these relations can remain dormant for some time before they are activated to set in motion coordinated actions. The continuity of these structures and the underlying consensus holding them together explain their conservative effect. Usually, policy networks defend an existing policy and provide for their continuity. However, strategic actors also mobilize networks and form coalitions in order to initiate policy change.

Paul Sabatier's 'Advocacy Coalition Framework' highlights the relevance of these actors and networks (Jenkins-Smith and Sabatier 1993; Sabatier 1987; Sabatier and Weible 2007). In his view, a policy field is characterized by different policy networks and a policy is stabilized by a particular power constellation among 'advocacy coalitions'. Decisions are based on proposals of different coalitions. They coordinate their conflicting strategies and find compromises with the help of 'policy brokers'. Shared beliefs or perceptions provide the glue holding together a coalition, while they cause divides between different coalitions. Under ordinary conditions, the balance of power in the policy system contributes to maintain continuity. Change is triggered by external events affecting the allocation of economic resources, social conflicts, public opinion or decisions in other policy subsystems. 
However, triggering change does not mean that it actually occurs. Sabatier and his co-authors certainly considered institutional rules and resources constraining action, but their focus is on belief systems guiding the behaviour of policymakers. To explain the change and continuity of a policy, Sabatier suggested distinguishing different dimensions of the 'belief systems' emerging in a coalition. In processes of socialization, individual members adopt fundamental world views. Related to the particular policies they are responsible for, they share a stable core of basic normative and ontological convictions with their fellows in a policy system. In addition, members of an advocacy coalition accumulate, continuously revise and advance knowledge on secondary aspects such as policy instruments or specific information. Accordingly, significant change of a policy requires that the dominating coalition revises its core beliefs, at least those related to a policy. This can be expected if the coalition risks losing power or if external events or crises compel participants to modify their basic assumptions. But in any case, changing core beliefs requires communicative interaction within an advocacy coalition.

\section{Policymaking as Communicative Interaction}

Sabatier and other scholars, who have applied and advanced his approach, developed a complex analytical framework which includes several mechanisms and conditions. What seems to be essential in this theory is the cognitive and normative dimensions of action. Yet in policymaking, it is not individual action which matters, but interaction. Accordingly, beliefs, that is 'views or opinions held by political actors that are relatively limited in scope or relate to relatively circumscribed areas of politics' (Berman 2013: 223-4), have to be turned into collective belief systems of a policy community or advocacy coalition. We can trace back a change in policies to processes in which actors revise their normative principles and assumptions about the causes and consequences of problems. But this only makes sense if we regard advocacy coalitions as intensely communicating groups of actors. External events might induce individual actors to learn, but policy learning results from dialogues and it affects the whole community of cooperating policymakers.

Other scholars have argued in a similar vein, although by using different terms (Berman 2013). The concept of core beliefs relates to the notion of cultures which integrates individuals into a community through processes of socialization and cooperation over a longer period. Policy-specific beliefs of individuals can turn into ideologies of groups. Unlike cultures, they are 'designed to achieve particular goals' (Berman 2013: 224). In the broad literature contributing to the ideational turn in policy studies and institutional theory, the same concept is designated as ideas, probably because ideologies used to be a term referring to fundamental political contests in a society or 
party politics. 'Ideational processes' are said to socially construct problems and issues. They influence the policy agenda and shape assumptions about how problems have to be solved or issues dealt with. Furthermore, ideas appear as 'discursive weapons' in political processes (Béland 2009: 702-5).

Ideas can be considered as a characteristic feature of institutions (Smith 1995: 137-9). Whereas organizations are defined by their purpose and rules, which are determined to coordinate actions, institutions integrate actors by a common 'spirit', which implies that they recognize specific principles and rules as appropriate, as 'at least under some conditions, functional and consistent with people's values and moral commitments' (March and Olsen 2013: 486). Rational actors abide by rules in order to avoid costs, whereas socialized actors accept them as consistent with their normative evaluation. Both the 'logic of consequence' and the 'logic of appropriateness' constitute mechanisms of path-dependence of institutions. The first can break off this continuity in a 'critical juncture' opening leeway for strategic action, the second can trigger change by communicative action. This can result in either a gradual or a significant, if not disruptive change.

In the ideational version of institutionalism elaborated by Vivien A. Schmidt (Schmidt 2010), actors are engaged in permanent discourses on the meaning and justification of institutions. In 'coordinative discourses', they construct ideas in the sense of shared cognitive frames, narratives and interpretations of rules. In 'communicative discourses', they reflect and revise their ideas. Both discursive processes overlap and combine to a continuous adjustment of the scope of action within the limits of acknowledged interpretations of rules. These mechanisms produce the same path-dependent evolution which is explained in different versions of historical institutionalism. Except for extraordinary events, discourses can neither transform power structures nor abolish or replace formal rules. Thus, they contribute to institutional continuity. However, in critical junctures, they might demarcate a new path of development.

Discursive institutionalist scholars who engage with the HI (Historical Institutionalism, AB) tradition, then, like HI scholars, also speak the language of institutional rules and regularities, critical moments and incremental change. It is just that they infuse these 'structures' with 'agency', by focusing on the ideas of real actors that help explain changes or continuities in institutions, at critical moments or incrementally over time. (Schmidt 2010: 13)

Robert Lieberman outlined another ideational approach to correct the bias of institutional theories which emphasize stability (Liebermann 2002). To this end, he takes ideas and institutions as distinct aspects of the social reality. Looking at political systems as a differentiated configuration of various 'layers' of institutions, he follows Paul Pierson when he argues that these layers 
result from a historical logic of change with new institutions being added to old ones. In addition, he concludes that ideas justifying institutions survive with old institutions while new ones emerge. Therefore, ideas and institutions do not form a coherent order, rather they constitute 'multiple concurrent orders' (Lieberman 2002: 702). At times, the ideological patterns and rules may fit together and complement each other, but at other times 'they will collide and chafe, creating an ungainly configuration of political circumstances that has no clear resolution, presenting actors with contradictory and multidirectional imperatives and opportunities' (ibid.). Hence there is a permanent tension between ideas and institutions (see also Orren and Skowronek 2004).

Radical change can occur if ideas evolve in a direction which contradicts the rules and norms enshrined in institutions and thus generate 'frictions'. They can also reveal a clash of diverging ideologies pertaining to an institution or conflicts with different layers of 'intercurrent' rules and authorities (Orren and Skowronek 2004: 118). Accordingly, a path-dependent evolution of a stable institutional order conceals tensions which can accumulate into rule conflicts or ideological antagonisms. In contrast to historical institutionalism, which is based on economic or sociological concepts of constrained actions, Lieberman presents a political science view highlighting internal contests for power and predominating narratives and justifications. By differentiating between institutional adaptation and communicative action as distinct and often contrasting mechanisms, he explains significant change as an endogenous process within institutions. This explanation takes communicative interaction not as a discourse in the sense of negotiation and arguing, but as a confrontation of, and contest for, ideas.

In policy studies, Peter Hall elaborated a similar line of theorizing when he introduced the concept of 'policy paradigms' (Hall 1993). In contrast to beliefs or ideas, paradigms signify the correspondence of continuity and change. Hall regards policy change as the result of a process of social learning in a policy field. Usually, learning evolves in an incremental process and affects the application and adjustment of policy instruments. Processes of these types of 'first and second order learning' involve policy specialists. 'Third order learning' leads to a change in policy paradigm and pertains to the basic assumptions and goals of a policy. It signifies a break with an existing policy and therefore gives rise to political disputes. Triggered by controversies among experts, the choice between an old and new paradigm turns into a matter of politics. Beyond scientific evidence or expertise, power becomes decisive for the outcome of a policy change. Yet it is not strategic action which drives change. Political actors have to decide on conflicting opinions of experts, and the 'authority' of these experts is a crucial factor influencing decisions (Hall 1993: 280). Therefore, providing reasons supporting one avenue of a policy compared to another is essential, and policy change does not result from a pure power game but rather 
from communicative interaction. This process diverges from the continuous discourses in that it is marked by contests and confrontation. It responds to failed policies and unintended or unexpected outcomes, and it challenges the arguments, if not the reputation, of policy experts. As Peter Hall put it,

the movement from one paradigm to another that characterizes third order change is likely to involve the accumulation of anomalies, experimentation with new forms of policy, and policy failures that precipitate a shift in the locus of authority over policy and initiate a wider contest between competing paradigms. This contest ... will end only when the supporters of a new paradigm secure positions of authority over policymaking and are able to rearrange the organization and standard operating procedures of the policy process so as to institutionalize the new paradigm. (Hall 1993: 280-81)

The distinction of different 'orders' of policy learning suggested by Peter Hall points out different mechanisms. In terms introduced by Vivien A. Schmidt, first and second order learning result from routinized communicative or coordinative discourses, that is in processes in which members of a policy community reflect on a policy and adjust instruments and implementation or revise a policy in order to better achieve their goals. Yet at some point, these discursive processes of policy learning by gaining experience and accumulating knowledge are interrupted, when communicative action turns into a debate on paradigms. One of the reasons for this disruption has to do with the fact that policy communities can become 'victims of group think' (Janis 1972), because their communication shields them from external influences and prefers information, interpretations and reasons which support the shared knowledge and opinions of the group. In these processes, knowledge evolves into a policy paradigm, which, as a social construct in general, implies self-reinforcing tendencies. However, it is exactly due to its growing rigidity that it also creates the cause for its contestation.

For Peter Hall, this contestation is triggered in the interface between state and society, in party politics and interest intermediation characterized by ideological competition. However, there is another important source of policy learning which may challenge existing policy paradigms. Lessons can be drawn from abroad (Rose 1993), by observing policies in other states, regions or local governments. Although a transfer of policies from one context to another regularly does not work due to different conditions, it can challenge conservative policy communities and instigate a process which, by way of introducing a new paradigm, can dissolve a policy regime. The monetarist approach in economic policy, which Hall used to illustrate significant change in the UK after the election of the Thatcher government, and the rise of New Public Management in public administration at about the same time can 
Mechanisms of policy change

\begin{tabular}{|c|c|c|}
\hline Process & $\begin{array}{l}\text { Mechanisms maintaining gradual } \\
\text { change }\end{array}$ & $\begin{array}{c}\text { Mechanisms producing substantial } \\
\text { change }\end{array}$ \\
\hline $\begin{array}{l}\text { Constrained } \\
\text { interaction }\end{array}$ & $\begin{array}{l}\text { - path-dependence } \\
\text { - positive policy feedback } \\
\text { - cooperation (voice and loyalty) }\end{array}$ & $\begin{array}{l}\text { - } \text { sequential process (punctuated } \\
\text { equilibrium) } \\
\text { - } \text { negative policy feedback } \\
\text { - competition (voice and exit option) }\end{array}$ \\
\hline Strategic interaction & - politics of veto players & - politics of political entrepreneurs \\
\hline $\begin{array}{l}\text { Communicative } \\
\text { interaction }\end{array}$ & $\begin{array}{l}\text { - continuous renegotiation of ideas } \\
\text { - routinized discourses } \\
\text { - group think in epistemic } \\
\text { communities }\end{array}$ & $\begin{array}{l}\text { - frictions between ideas and } \\
\text { institutions } \\
\text { - paradigm shift } \\
\text { - policy learning }\end{array}$ \\
\hline
\end{tabular}

demonstrate these particular kinds of policy learning. In both cases, the new paradigm started its career in the US and left its mark in many Western states.

Table 3.1 summarizes the mechanisms which can be drawn from the broad literature on institutional and policy change. Given the multitude of publications during the last three decades and the growing differentiation of analytical approaches, conceptual frameworks and explanations, it is hardly possible to clearly discern particular theories. There is much more overlap than divergence and broad agreement between scholars using different labels to brand their explanation of change. In empirical research, theories have been further elaborated and refined (see, e.g., Broschek et al. 2017; see also Beyer 2010; Pierce et al. 2020; Skogstad 2011; Weible and Sabatier 2017). Notably, we find significant correspondence between theories explaining institutional change and those explaining policy change. This is not surprising if we acknowledge that policy change results from interaction of different kinds of actors, from an interplay of constrained, strategic and communicative interactions, and that it affects institutions. Therefore, rather than selecting one of the proposed theories and denying others, it seems more promising to combine them into a conceptual framework for empirical research, a framework which allows us to derive hypotheses for particular cases or comparative case studies.

\section{CONDITIONS OF POLICY CHANGE}

As mentioned above, mechanisms operate under varying conditions which can be decisive for the outcome in a particular case. Including conditions does not mean that we can only explain individual cases without being able to generalize findings of empirical research. Not only can we discover mechanisms as causal processes operating in different cases, but we can also identify types of conditions presuming that they have similar effects in multiple cases. 
Literature on policy change points to a set of such conditions. They can arise from external developments or can be created by the strategic action of policymakers, and their impact depends on whether influential actors in a policy field perceived them as relevant or not. Here, I will focus on external developments which elude strategic action and can hardly be ignored by political actors.

Social, economic, ecological and technological developments constitute a first set of conditions affecting policymaking. There is no doubt that governments in democracies have to respond to social conflicts, that their capacity to govern depends on resources collected in public and private economy, that pollution of soil, water and air became a primary challenge for governments and that dealing with these challenges depends to a significant extent on available technologies. Turbulence resulting from international politics can be added in this list of conditions. Changes in these external conditions certainly can make policy change indispensable. However, for a number of reasons is it impossible to draw generalizable conclusions. First, none of the external developments constitutes objective determinants for politics, as nowadays even Marxists would admit. Whether the consequences resulting from them are defined as issues of government is a matter of politics on its own. Beyond the power to make decisions, the 'mobilization of bias' in the agenda-setting process is the second face of power to be considered in politics (Bachrach and Baratz 1962: 949), the power to define issues as relevant for politics or not. Second, governments often do not react to these challenges immediately and often with significant delay. Social policy in the face of demographic change and energy policy in view of climate change are cases in point, not to mention issues like the social and racial discrimination of particular groups in society. Third, governments do not react as coherent collective actors. More often than not, problems are on the agenda of departments or expert bodies before they appear as an issue in cabinets or in legislation, and the different timing of responses within governments is a reason for the punctuated evolution of agenda setting, as described by Frank Baumgartner and his colleagues (Baumgartner et al. 2017). Of course, the effects of societal conditions on policymaking should not be neglected. However, as regards policy change, we cannot generalize on these effects.

Social developments often become manifest in a crisis, and crises are often regarded as situations enforcing significant change. There is no doubt that they can shock a society and destabilize a political system. Whether they prompt a government to change its policy or increase the pressure for change, as is often assumed, is another question. In the US, the New Deal of President Roosevelt in the 1930s or President Johnson's 'War on Poverty' in the 1960s might exemplify a significant policy change in a social crisis, and in many Western states social policy made big strides after the two world wars. But in these exceptional situations, much depends on bold political leadership 
and fiscal and administrative capacities. In a crisis, governments usually concentrate power at the central level, in the executive or special staffs, and the public regularly calls for leadership. In democracies, however, crisis management puts political leaders under pressure of public opinion (Carlisle et al. 2017), and a consensus in society and among parties remains fragile (Boin et al. 2016), as has become evident in the COVID-19 pandemic. Faced with significant uncertainty about the causes and development of a crisis and the appropriate consequences of policies, governments often tend to avoid high risks and rely on established practices. This was the case after the fall of the Berlin Wall in 1989 had accelerated the collapse of the communist regime in the German Democratic Republic and the process of German unification. Thereafter, federal and Länder governments transferred the portfolio of established policies to East Germany and avoided all reform experiments. More often than not, crisis management proceeds in an incremental way, and soon after the immediate shock has calmed down a consensus on the need for policy change or institutional reform fades away in disputes on the assessment of, and the responses to, the crisis (Boin et al. 2016: 126-44; Peters 2016).

In a crisis of a political system or an institution, a critical juncture can open. The collapse of a regime, the dissolution of a federation into independent states or the unification of states to a federation are cases in point, as are scandals revealing the ineffectiveness of particular institutions or control deficits. Even in stable states, crises can create a 'constitutional moment' (Ackerman 1993). Under these conditions, existing rules and practices either no longer work as designed or they come under attack in cabinets, parliaments or public discussions. In consequence, 'protean power' can emerge 'as the effect of improvisational and innovative responses to uncertainty that arise from actors' creativity and agility in response to uncertainty' (Seybert and Katzenstein 2018: 4). However, where this power comes from and how it can be organized is all but clear. Therefore, as outlined above, critical junctures do not necessarily prompt a significant change in policy. As Vivien A. Schmidt rightly emphasized, such a situation sets off a political process with the outcome depending on the discourses on different alternatives (Schmidt 2010: 13). While institutional constraints are weakened and power relations might change accordingly, strategic and communicative interaction prevails. Yet strategies might fail and discourses can turn into bargaining or confrontation. Actors might miss the opportunities of a critical juncture, or they avoid the risks which come with significant policy change and modify the institutional form but not the substance of a policy.

A change of government after an election seems regularly to lead to a policy change. In any case it is the function of elections to enable a revision of policies. When a majority of voters removes an incumbent government, they do not aim to replace the office holders in the first place, rather they use this pos- 
sibility provided by democracy to achieve a new policy. Unlike as suggested by a minimalist understanding of democracy (Przeworski 2019: 5; Schumpeter 1943 [2010]: 241-5), competitive elections are not merely a contest for power but a process of holding elected representatives accountable for their decisions and of determining the future direction of policymaking. Therefore, from a normative point of view, one should expect that elections concern the substance of policies, and a change in government should bring about a substantial change in policy.

However, this is not always the case. Even if we assume that parties offer distinct programmes and that the party in power is able to implement its programme and related policies, those holding governmental offices or a majority of votes in the legislature do not simply implement the 'will of the people' or of the majority of voters, irrespective of whether they have any clue what this will means. Interested in getting re-elected, they intend to pursue the public interest instead of an aggregation of individual interests expressed in an election. In representative democracy, members of parliaments or directly elected executives are not committed to an imperative mandate of their voters, rather they are - ex post - accountable for the policies they have made and for the outcomes they are responsible for. Therefore, they are and should be relatively autonomous in the way they govern. When they deviate from a presumed will of the voters, they do not necessarily face negative consequences in elections. By engaging in debates with opposition parties, interest groups and the media, majority parties and members of the executive can explain and justify their proposed or realized decisions and actions in policy-oriented public discourses (Majone 1989; Scharpf 2000: 118-20).

For this reason, elections do not necessarily stimulate policy change. A newly elected government operates under the same constraints as the previous one. While in majoritarian democracies it is more likely that a change in government brings about a policy change, in pluralist democracies with proportional elections parties have to form coalition governments and find compromises on policies. In federal democracies, bicameral legislatures may endow opposition parties with veto power, and governments have to negotiate agreements in intergovernmental relations. Policies might reveal the 'kinder and gentler qualities' of these 'consensus democracies' (Lijphart 1999: 300). However, continuity may become a burden for democracy, which requires the possibility for effective policy change, whenever elections had signalled that a majority of citizens prefers a new course.

Various institutional and situational conditions can trigger policy change, but this does not mean that at the end of a process which is driven by various mechanisms policies have really changed. Moreover, triggering events regularly have no impact on the direction in which a policy develops. They can facilitate intended change, but these events can also set off unintended 
Outcomes of policy change

\begin{tabular}{cccc}
\hline & Gradual & Substantial & Transformative \\
\hline \multirow{2}{*}{ Intended (successful) } & adaptation & amendment & transformation \\
\cline { 3 - 4 } & & \multicolumn{2}{c}{ policy innovation } \\
\hline Failed & rigidity & deadlock & regression \\
\hline Unintended & drift & evolution & crisis \\
\hline
\end{tabular}

processes and outcomes (for an example: Benz and Sonnicksen 2018). In any case, they rarely favour policy innovation. In complex multilevel governance, we often find many conditions having an impact on policymaking. For these reasons, external factors need to be considered, but explanations have to be based primarily on mechanisms.

\section{FROM GRADUAL CHANGE TO POLICY INNOVATION?}

Policy change finds expression in outcomes which diverge from the status quo in some way or another. In the previous sections, I have distinguished incremental and significant change, which may materialize intendedly or unintendedly. Significant change can affect the substance of a policy but can also relate to structures and institutions established in a policy regime. In the latter case, it has transformative implications. Moreover, intended change can succeed, but it can also fail. Table 3.2 locates policy innovation in this analytical framework categorizing different outcomes of policymaking. As indicated in the table, substantial and transformative change can result as unintended consequences of governance, particularly when responsible actors lose control. Failure of incremental or gradual change can prevent adaptation with the consequence that either a policy drifts in a direction that is not envisaged by responsible office holders or results in increasing rigidity within a policy regime. Failed innovation is revealed in a deadlock of an amendment and turns into a regressive development when opponents of a transformation exploit the opportunity of such an occurrence to return to a previous path-dependent development. When the promises which a government has made with an innovative policy agenda turn out as exaggerated, disappointed actors can try to advance their aims outside established institutions and procedures, although they risk unintended consequences by proceeding in this way. Thus, unintended and uncontrolled substantial and transformative dynamics and failure of an innovative policy can lead to a serious crisis of a government, if not a political system. Therefore, understanding the mechanisms of policy innovations and the causes for failure are highly important. 
What are the mechanisms which are conducive for policy innovation and which conditions appear favourable for this kind of change? As a review of the growing literature on public sector innovation reveals, varieties of strategic and communicative interaction appear to be main drivers of innovative policymaking. Proponents of New Public Management have emphasized competition for best practices, monitoring in decentralized structures and feedback from peer reviews as essential procedures to make public administrative not only efficient, but also innovative. Meanwhile, scholars have raised doubts about these assumptions. Instead, collaboration, networks and discourses are praised as patterns of governance stimulating new ideas and practices and promising to solve problems (Ansell and Torfing 2014a; Sørensen and Torfing 2015; Torfing and Triantafillou 2016b). We also find models of innovation processes, most of them being derived from theories of policy learning or diffusion of innovation (e.g., Daniell et al. 2014). Change agents, innovation brokers or policy entrepreneurs are considered as most relevant actors in innovation processes in this context.

Without going into further details of this literature and research field, it seems obvious that policy innovation results from strategic action which is determined by, and capable of, overcoming obstacles of institutional rules, self-reinforcing dynamics and lock-in effects resulting from interactions in exclusive networks or policy coalitions, routinized practices and prevalent policy paradigms. In short, strategic action in this context aims at revising incrementalist logics of policymaking. In addition, patterns of communicative interaction are essential to stimulate inventions of new policies, to change belief systems of policy communities and to enable a paradigm shift in public policies. Communication also serves to persuade actors to adopt innovation and to circulate relevant information in a policy regime.

Presumably, innovative policies are more likely to emerge in communication among experts and in so-called 'epistemic communities' (Haas 1992), provided that experts can work independently or at a certain distance from politics and administration. On the other hand, experts might not be heard in policymaking if they provide ideas which do not relate to a specific problem to be solved or a particular context. For this reason, expertise alone is not sufficient. Rather, it is the structuring of communication which both differentiates epistemic communities from communities of policy officials and links these communities with regular communicative processes in politics and administration. In a recursive process coupling these arenas of communication and negotiation, it is possible that contests in party politics, conflicts among different departments in administration or disputes among special interest groups challenge experts to find new solutions in a discursive process. When the outcomes of this discourse are fed into political processes, they can dissolve confrontations and modify bargaining processes by challenging the rigid 
claims of actors. Unlike theories of agenda setting and policymaking suggest, which trace back significant change to coincident focusing events or windows of opportunities and the existence of policy entrepreneurs in these situations, the structuration of communicative interactions in a policy regime seems to be more relevant to bring about policy change and innovative solutions to problems at hand.

However, new paradigms or ideas do not suffice. They have to become effective under the constraints of institutions, politics and existing public policies. Therefore, strategic action and interaction are relevant as well. In view of the rigidity of institutions and path-dependent dynamics, scholars working on institutional change have drawn attention to particular strategies to circumvent constraints. In her research on governance in the EU, Adrienne Héritier has discovered 'interstitial institutional change' occurring between formal rule revisions (Héritier 2007: 45-51). In studies on constitutional policy, a similar process has been conceptualized as 'implicit change' (Voigt 1999) or the amendment of a constitution by non-constitutional means (Lazar 1997). This process evolves within existing institutions, it is driven by endogenous forces and usually leads to incremental adjustment of informal rules or interpretation of rules in 'communicative discourses' (Schmidt 2010: 3) among actors applying rules. However, as Héritier suggests, and as has been confirmed in research on constitutional change (Benz 2016a), a reinterpretation or adjustment of rules can also mean a step towards a more comprehensive renovation, as institutions constitute 'incomplete contracts'. Therefore, 'informal rules which emerge in the specification and renegotiation of an existing formal institutional rule in a second time may also affect the next bargaining round in the revision of the formal institutional rules and lead to a formalization of the "interstitial change" that has occurred' (Héritier 2007: 47). In general, Héritier expects 'that formalization will happen when all actors agree that the informal rule should be formalized because it is beneficial to all' (ibid.: 48). But even in cases of disagreement on the precise formulation of new rules, emergent new practices can exert significant pressure on veto players in the ensuing reform process, not least if advocates of innovation can draw attention to a divergence between ideas and realities of institutions.

This strategy works to change institutions and constitutions, depending on the density of formal rules and the latitude of actors to implement rules. In normal policymaking, comparable strategies come to limits, because implementing actors working in different local contexts are not able to coordinate their practices and interpretations. Nonetheless, discrepancies between intentions and the implementation of a policy can induce a revision initiated by opposition parties or regional or local governments. What has been discussed in the literature as policy feedback can turn into a strategy aiming at policy innovation. The institutional differentiation of central policymaking and 
decentralized implementation and established linkages between both arenas constitute essential conditions for this strategy to become practicable.

Regarding strategic action, political leadership seems to be of particular relevance to advance policy innovation. However, even charismatic leaders of governments or parties who come to office with new ideas have to realize the constraints of institutions, power relations and policy legacies. In presidential systems like the US, political leadership may be able to induce significant change (Orren and Skowronek 2004; Skowronek 2008), but as President Obama's health care reform exemplifies, the fate of a policy innovation nonetheless depends on the support of an administration, the power of interest groups, the majority in a legislature and, last but not least, the implementation by administrative or regional or local authorities (Jacobs and Skocpol 2014). While political leaders have the power to define an innovative agenda of policymaking, the process of innovation requires actors who are able to strategically orchestrate the collaboration of different participants, appropriately link arenas and sequences, moderate conflicts without suppressing disputes, facilitate negotiations on policy proposals and prevent the watering down of innovative elements in bargaining processes. In view of the variety of challenges to be met, a steering committee of actors with different competences seems to be better suited than an outstanding political leader. Accordingly, Sørensen and Torfing recommend a combination of adaptive and pragmatic leadership of actors who adopt the roles of 'convenors', 'facilitators' and 'catalysts' (Sørensen and Torfing 2015: 156-61). The politics of policy entrepreneurs or progressive advocacy coalitions promoting a new policy also contribute to innovation as far as they mobilize support for change, initiate or design processes, and create a supportive environment in politics and public administration.

In their comprehensive volume on innovation in the public sector, Jacob Torfing and Peter Triantafillou suggest a transformation of public governance so that policy innovation and institutional reform become feasible (Torfing and Triantafillou 2016b). The authors make the case for collaboration within the public sector as well as between public agents and private stakeholders. Furthermore, they argue for institutional diversity to stimulate competition and experimentation and a trust-based management supported by political leadership. Their theoretical framework combines the core concepts of institutions, governance and innovation in order to define structures and processes that are both conditioning or constraining and transforming:

Institutions are characterized by a relatively high degree of stability, and governance is predicated on the presence of a relatively stable set of rules, routines and procedures that facilitate interaction and give rise to particular modes of governance, while allowing for some degree of flexibility in the concrete acts of governing. By 
contrast, innovation involves a deliberate effort to disrupt stable ideas and practices and create new ones in the hope that these will outperform the previous ones ... (P)ublic governance is conditioned by the institutionalization of rules, norms and procedures that guide and channel the process of governance, which in turn condition the attempts to innovate. Successful innovation will sometimes transform the structures and forms of governance, which will in turn transform the institutional underpinning of public governance. (Torfing and Triantafillou 2016a: 22-3)

The contributions to their edited volume discuss the different patterns of interaction, structures and strategies which Torfing and Triantafillou deem relevant in policy innovation. Most of the authors find ambivalent effects of these patterns such as leadership, collaboration in networks, public-private cooperation, monitoring and accountability relationships. This demonstrates that particular factors or mechanisms alone cannot guarantee policy innovation. Apparently, it is the combination of stability of institutions, dynamics of strategic interaction and discursive processes revising the substance of a policy which ultimately provide an appropriate setting for policy change. In order to avoid the scenario that constrained interaction prevents change and that strategic action makes change a matter of power politics, a dominance of these processes over communicative interaction needs to be avoided. This is possible if policymaking is organized in distinct arenas characterized by different actor constellations and different modes of interaction, and if the processes in these arenas are linked in an appropriate way (Benz 2016a).

If innovation can be generated by an appropriate 'meta-governance' of distinct processes, not only the substance but also the dynamics of policymaking itself changes, as has been highlighted in innovation studies focusing on firms and markets (see Fagerberg et al. 2005). It is less the 'creative destruction' (Schumpeter 1943 [2010]: 73) of a competitive process, but rather the fact 'that every new innovation consists of a new combination of existing ideas, capabilities, skills, resources, etc.' (Fagerberg 2005: 10) which matters. This dynamic process, which is fed by strategic and communicative interaction, can over a longer run affect a whole policy regime and end in a transformative change. In the public sector, a revival of conservative forces working against innovation and transformation is more likely than in private firms, as long as policy change is not supported by a change in power structure and institutions.

\section{CONCLUSION}

This review of theoretical approaches to explain policy change and innovation only covers a small part of the literature in a booming research field. Still, many of the contributions to this literature either suggest that the usual gradual evolution of institutions and incremental policy adjustment is interrupted under a particular concurrence of external events, endogenous development and the 
strategic action of political leaders or policy entrepreneurs. However, in the different models of this sequential process, the shift from continuity to disruptive change appears under contingent, uncontrollable circumstances which are not foreseeable. Concepts such as focusing events, windows of opportunity, punctuated equilibrium or critical junctures all reveal this indeterminacy in the explanation. The inclusion of strategic actors does not fully close this gap. Patterns like networks, advocacy coalitions or discursive coalitions need to be included to understand why a policy changes in a particular direction and why innovation might occur.

Hence the linkage of different patterns of interactions in distinct arenas should be taken into consideration. In consequence, irrespective of whether creative actors, political leaders or inventive policy entrepreneurs as well as policy networks or experts and advisory bodies contribute to policy change, it is the complexity of institutions and governance that constitutes an essential condition for significant policy change and innovation. Complexity allows the combination of different mechanisms of policymaking contributing to the generation and implementation of new ideas, rules, procedures, policy instruments and practices. In view of the particular complexity of structures and processes, it stands to reason that multilevel governance is especially conducive to significant change. I will discuss this assumption in the next chapter.

\section{NOTES}

1. The status quo in a policy field can also change significantly without political decisions, not only because governments fail to address problems but also because they willingly avoid deciding on issues. For an example of the latter alternative see Hacker 2005: 49-68.

2. As this chapter outlines the causes and conditions of policy change and discusses relevant theories, there is no need to discuss different proposals and methodological problems to measure policy change (see Howlett and Cashore 2009). 